\title{
Case-control study on the association between a cluster of childhood haematopoietic malignancies and local environmental factors in Aalsmeer, The Netherlands
}

\author{
Yonne M Mulder, Marjon Drijver, Irene A Kreis
}

\begin{abstract}
Study objective and design - In Aalsmeer, a horticultural community near the main international airport in The Netherlands, a more than fourfold increase in the incidence of haematopoietic malignancies in young people was observed between 1980 and 1985. In a population based case-control study, the association with local environmental factors was investigated.
\end{abstract}

Participants - For each patient younger than 40 years of age $(n=14)$ diagnosed between 1975 and 1989, four age and sex matched controls were selected via local general practitioners.

Methods - All parents of patients and controls completed a questionnaire on their lifestyle, living conditions, and health, for several years preceding each individual diagnosis. Odds ratios (ORs) with $95 \%$ confidence intervals (CI) were calculated, matched, and, if necessary, stratified for neighbourhood.

Main results - Increased ORs were recorded for intensive use of petroleum products and pesticides by the patients themselves and their fathers: $O R$ petroleum products: $8 \cdot 0(95 \%$ CI $2 \cdot 2,129 \cdot 9)$ and 9.0 (1.0,66.1) respectively; $O R$ pesticides: $6 \cdot 0(0 \cdot 6,49 \cdot 3)$ and $3 \cdot 2(1 \cdot 0,10 \cdot 1)$ respectively. Swimming in a local pond was also significantly associated with the disease: $O R=5 \cdot 3(1 \cdot 3,17 \cdot 4)$. In the 1970 s this pond had been polluted by petroleum products and pesticides.

Conclusions - The increased incidence of childhood haematopoietic malignancies in Aalsmeer may have been associated with several specific local environmental factors. Interpretation of the results, however, should take into account the fact that confidence intervals were wide because of the limited number of cases.

(f Epidemiol Community Health 1994;48:161-165)

In 1985 a cluster of cancer cases was observed in the horticultural municipality of Aalsmeer. The parents of a boy who died of leukaemia reported to their paediatrician that they knew 12 people with a "similar" disease within a radius of $1 \mathrm{~km}$. They wondered whether swimming regularly in a pond or the proximity of Schiphol airport could be causes. They suspected that the pond was polluted by pesticides and petroleum products.

Aalsmeer is one of the world's main centres for flower cultivation. Almost all flowers are grown in greenhouses. Pesticides are used intensively but in order to meet all international regulations. Aalsmeer is within $5 \mathrm{~km}$ of the main Dutch international airport, Schiphol, and has few, but very busy, roads. The municipality can be divided into western and eastern parts. Most people live in the western neighbourhood, which is located near a popular water recreation area. All reported cases were living in the less populated, more horticultural eastern part. Almost all the greenhouses are located in the east as well as another water recreation area which is permanently connected with the draining ditches of the greenhouses.

An investigation was started because an association between leukaemia and occupational exposure to pesticides, petroleum products, and exhaust gases had been described. ${ }^{1}$ An association between a leukaemia cluster and local environmental pollution, other than radiation, ${ }^{2}$ has been described before in Woburn (MA, USA), like Aalsmeer known for its flower cultivation, ${ }^{3}$ where a relationship was suggested with drinking water from a source contaminated with solvents. ${ }^{4}$ More recently a relationship was reported between leukaemia and living near busy roads. ${ }^{5}$

In those inhabitants of the entire municipality of Aalsmeer younger than 40 years of age, a more than fourfold increase in the incidence of leukaemia for the period 1980-85 was confirmed by the evaluation of routine nationwide disease registries. ${ }^{6}$ This suggested that the incidence in the area where most of the cases were concentrated was considerably higher than average. The limit of 40 years was chosen because of a natural break in age incidence curves of leukaemia.

An investigation of local environmental pollution showed that surface water and soil samples in and around a natural swimming pond in the eastern water recreation area exceeded the acceptable limits for pesticides (including DDT), polycyclic aromatic hydrocarbons (PAHs), and benzene. In the 1970s, a pesticide store on the border of the suspect pond had been burned out; there had also been an accident with a large fuel oil tank in adjacent waters.

It was therefore decided to start a casecontrol study. Because of the diagnostic and 
aetiological similarities between the most common leukaemias and lymphomas in younger people, ${ }^{7}$ lymphoma as well as leukaemia cases were included in the study, thus doubling the research group.

The question under investigation was whether patients had experienced more contact with local environmental factors than control subjects through:

Exposure to pesticides used in intensive horticulture (greenhouses);

Swimming in water polluted by horticultural procedures; and

Local air pollution.

General risk indicators for haematological malignancies known from epidemiological studies were also investigated, since these could interfere with the assumed relationship.

\section{Methods}

The local general practitioners covering the entire municipality of Aalsmeer reported eight leukaemia and seven lymphoma cases aged under 40 years for whom a pathologically and anatomically verified diagnosis had been made in the period $1975-89$.

In The Netherlands everybody is registered with his own general practitioner. For each patient, four control subjects of the same gender and age (with a spread of six months) were selected from the alphabetical registry of the patient's general practitioner, without consideration of the neighbourhood of residence. The first four names following the patient's name were selected, excluding identical surnames. Patients and controls who, at diagnosis of the disease, had lived in Aalsmeer for less than three years were not included in the study. This entailed the exclusion of one adult leukaemia case who came to live in Aalsmeer one year before the diagnosis.

At the beginning of 1989 the parents of patients and controls were requested to complete a questionnaire. Questions about the degree of exposure to chemical substances such as petroleum products as a result of work or leisure activities referred to the period preceeding diagnosis of the malignancy of the matched case control set. For subjects over 21 years of age, who all were alive, these questions about exposure during adulthood were completed by the subjects themselves; in view of a potentially longer latency period, they were asked about possible exposure as teenagers too.

Exposure to pesticides was divided into direct contact (using pesticides oneself), indirect contact (working in horticulture), use of pesticides by the parents, playing in greenhouses as a child, and distance between home and greenhouses. From these risk indicators a sum-score parameter was calculated as overall indicator for potential exposure to pesticides.

Outdoor recreational activities (like swimming) were expressed in terms of the number of hours per week spent on the activity during the summer season.

Because of the lack of quantitative exposure parameters for air pollution, an indirect measure was obtained. Questions were asked about annoyance from odour, dust, and noise, and the number of hours spent in the open air. The consumption of locally grown food was asked about in connection with possible pollution of food crops by deposits from the air.

Statistical analyses consisted of calculation of matched odds ratios (ORs) with the corresponding $95 \%$ confidence intervals $(95 \% \mathrm{CI})$ according to Miettinen. ${ }^{8}$ To reduce confounding by extreme differences in (proximity to) neighbourhood exposures between cases and controls, ORs for all specifically local risk indicators were stratified by neighbourhood, using the Mantel-Haenzel method, with $95 \%$ CIs according to Cornfield (one sided calculation: $\alpha<0.05)$. The aetiological fraction was calculated according to Miettinen. ${ }^{9}$ Because of the small numbers, logistic regression analysis was not considered useful.

\section{Results}

There were seven cases of leukaemia (six male; one female). Six patients had acute lymphoid leukaemia and one acute myeloid leukaemia. The median age of these cases was 6 years. Of the seven lymphoma cases (six male; one female) six had non-Hodgkin's lymphoma and one Hodgkin's lymphoma; the median age was 25 years. The leukaemia cases, in particular, tended to cluster in the early 80 s (figure).

The participation rate was $100 \%$ in patients $(n=14)$ and controls $(n=56)$. The mean (SD) time taken to complete the questionnaire was 62 (27) minutes in the cases and 54 (32) minutes in the control group. This difference was not statistically significant.

The most significant ORs for acknowledged risk indicators, including $95 \% \mathrm{CIs}$, are presented in table 1 . Chemical exposure indicators of the subjects themselves and of their fathers resulted in high ORs, especially for intensive use of petroleum products (mostly lubricating oils). The calculated aetiological fraction for exposure to petroleum products of the subjects themselves (that is, the proportion of the disease that is related to petroleum products) was $81 \%$ in exposed cases and $23 \%$ in all cases; aetiological fractions for fathers' exposure to petroleum products were $70 \%$ and $20 \%$ respectively. Too few mothers had been

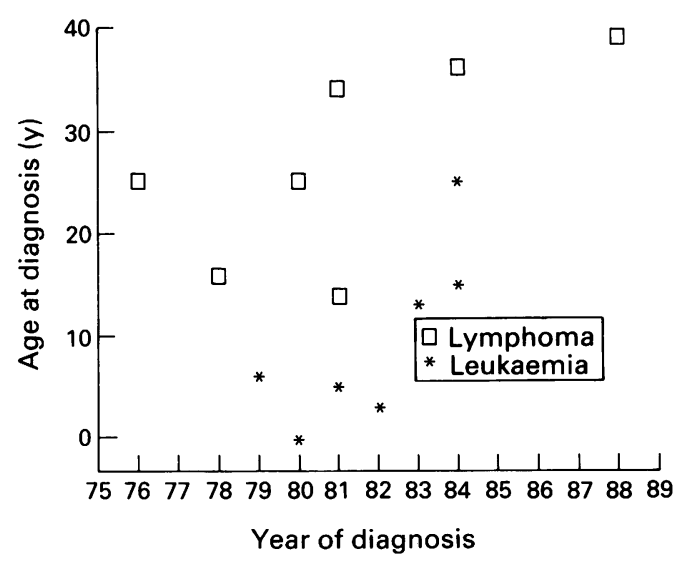

Age at diagnosis of haematopoietic malignancy. 
Table 1 Acknowledged risk indicators for haematopoietic malignancies in cases $(n=14)$ and controls $(n=56)$ in Aalsmeer, The Netherlands

\begin{tabular}{|c|c|c|c|c|c|}
\hline \multirow[t]{2}{*}{ Variable } & \multirow[t]{2}{*}{ Patients $(\%)$} & \multirow[t]{2}{*}{ Controls $(\%)$} & \multicolumn{3}{|c|}{ Odds ratio $(95 \% \mathrm{CI})$} \\
\hline & & & Matched & Crude & Stratified \\
\hline \multicolumn{6}{|l|}{ Subject: } \\
\hline Rank order of child (oldest) & 36 & 32 & $1 \cdot 3(0 \cdot 4,3 \cdot 7)$ & $1 \cdot 2(0 \cdot 3,4 \cdot 7)$ & $1 \cdot 8(0 \cdot 3,10 \cdot 2)$ \\
\hline Do it yourself activities & 21 & 5 & $5 \cdot 5(1 \cdot 1,26 \cdot 6)$ & $4 \cdot 8(0 \cdot 6,39 \cdot 8)$ & $2 \cdot 9(0 \cdot 3,44 \cdot 4)$ \\
\hline Exposure to petroleum products (yes no) & 29 & 5 & $5 \cdot 3(2 \cdot 0,121 \cdot 6)$ & $7 \cdot 1(1 \cdot 1,49 \cdot 8)$ & $\uparrow\left(0^{\circ}\right.$ contr $)$ \\
\hline Exposure to petroleum products ( $\geq 3 \mathrm{~h}$ wk $)$ & 29 & 4 & $8 \cdot 0(2 \cdot 2,129 \cdot 9)$ & $10 \cdot 8(1 \cdot 4,102 \cdot 8)$ & $\uparrow(0 \%$ contr $)$ \\
\hline \multicolumn{6}{|l|}{ Mother: } \\
\hline Age at birth $\geq 37$ years & 7 & 9 & $0 \cdot 8(0 \cdot 1,2 \cdot 9)$ & $0 \cdot 8(0 \cdot 0,8 \cdot 0)$ & $0.8(0.0,11 \cdot 9)$ \\
\hline Miscarriage in family & 50 & 36 & $2 \cdot 0(0 \cdot 7,4 \cdot 9)$ & $1.8(0.5,6.9)$ & $1 \cdot 4(0 \cdot 2,8 \cdot 4)$ \\
\hline \multicolumn{6}{|l|}{ Father: } \\
\hline Risk occupation (chemical) & 86 & 59 & $6 \cdot 0(1 \cdot 1,59 \cdot 8)$ & $4 \cdot 2(0 \cdot 8,41 \cdot 3)$ & $6 \cdot 0(0 \cdot 6,288 \cdot 8)$ \\
\hline Exposure to petroleum products (yes no) & 29 & 13 & $3 \cdot 3(0 \cdot 9,12 \cdot 9)$ & $2 \cdot 8(0 \cdot 6,14 \cdot 0)$ & $\uparrow\left(0^{\circ} \%\right.$ contr $)$ \\
\hline Exposure to petroleum products ( $\geq 3 \mathrm{~h}$ wk $)$ & 21 & 7 & $9 \cdot 0(1 \cdot 0,66 \cdot 1)$ & $3.6(0.5,23.4)$ & $\uparrow\left(0^{\circ}\right.$ o contr $)$ \\
\hline \multicolumn{6}{|l|}{ Family: } \\
\hline Heavy smoking & 36 & 25 & $1.9(0 \cdot 6,6 \cdot 4)$ & $1 \cdot 7(0 \cdot 4,6 \cdot 9)$ & $2 \cdot 7(0 \cdot 4,18 \cdot 0)$ \\
\hline
\end{tabular}

Matched = matched for age and gender; Crude= unmatched and unstratified; Stratified=stratified for residence in the eastern of two neighbourhoods with reasonable proximity to greenhouses and suspect pond.

exposed to chemical substances for the calculation of reliable ORs.

Table 2 gives an overview of the local risk indicators. In both the case group and the control group a comparable percentage of respondents had been in contact with pesticides. However, the intensity of exposure differed: for those who were exposed for three hours per week or more an OR of $6 \cdot 0(95 \%$ CI $0 \cdot 6,49 \cdot 3)$ was recorded, even after stratification for neighbourhood. Except for neighbourhood, the other risk indicators (including petroleum products) were not associated with contact with pesticides.

When the group of cases was broken down into category of diagnosis, the OR for leukaemia was particularly high for the patients whose fathers had intensive contact with petroleum products and pesticides. For the lymphoma cases, whose average age was older, their own exposure to these chemicals showed higher ORs.

ORs were calculated for water sports for the children who were 6 years or more at diagnosis $(\mathrm{n}=50)$. A minimum of one hour's swimming per week in the polluted eastern pond pro- duced an OR of $5 \cdot 3(1 \cdot 3,17 \cdot 4)$; stratified according to neighbourhood $(\mathrm{n}=28)$ this was $3.8(0 \cdot 5,45 \cdot 6)$. The aetiological fraction was $74 \%$ for exposed cases living in the eastern neighbourhood and $56 \%$ for all cases living there. When the family who had suggested the relationship with swimming was omitted, the OR was $3 \cdot 5$. Because exposure to petroleum products during hobby or occupation was associated with swimming behaviour, stratification was applied for exposure to petroleum products; the OR for the group not exposed to petroleum products dropped as a result to $2 \cdot 7$ (NS). No raised OR was found for swimming in the unpolluted western pond.

ORs for all air pollution indicators exceeded 2. Local vegetable consumption was associated with exposure to pesticides, therefore stratification was applied to this aspect. For those with intensive pesticide exposure the OR dropped to $2 \cdot 0$ (NS).

\section{Discussion}

Since cases tend to cluster around the closest general practice, matching the controls by

Table 2 Local risk indicators for haematopoietic malignancies in cases ( $n=14$ ) and controls ( $n=56)$ in Aalsmeer, The Netherlands

\begin{tabular}{|c|c|c|c|c|c|}
\hline \multirow[t]{2}{*}{ Variable } & \multirow[t]{2}{*}{ Patients (\%) } & \multirow[t]{2}{*}{ Controls $(\%)$} & \multicolumn{3}{|c|}{ Odds ratio $(95 \% \mathrm{CI})$} \\
\hline & & & Matched & Crude & Stratified \\
\hline \multicolumn{6}{|l|}{ Pesticides } \\
\hline \multicolumn{6}{|l|}{ Subject: } \\
\hline Short distance from greenhouses & 71 & 45 & $3 \cdot 5(1 \cdot 1,19 \cdot 6)$ & $3 \cdot 1(0 \cdot 8,15 \cdot 0)$ & $1 \cdot 9(0 \cdot 3,21 \cdot 8)$ \\
\hline Playing in greenhouses & 29 & 16 & $2 \cdot 4(0 \cdot 7,10 \cdot 1)$ & $2 \cdot 1(0 \cdot 4,9 \cdot 8)$ & $1.7(0 \cdot 3,10 \cdot 5)$ \\
\hline Holiday job in greenhouses & 29 & 25 & $1 \cdot 3(0 \cdot 4,4 \cdot 3)$ & $1 \cdot 2(0 \cdot 3,5 \cdot 2)$ & $2 \cdot 7(0 \cdot 4,18 \cdot 0)$ \\
\hline Exposure to pesticides (yes no) & 14 & 14 & $1 \cdot 0(0 \cdot 2,4 \cdot 2)$ & $1 \cdot 1(0 \cdot 0,6 \cdot 3)$ & $1 \cdot 3(0 \cdot 1,11 \cdot 4)$ \\
\hline Exposure to pesticides ( $\geq 3 \mathrm{~h} / \mathrm{wk})$ & 14 & 5 & $6 \cdot 0(0 \cdot 6,49 \cdot 3)$ & $2 \cdot 9(0 \cdot 2,28 \cdot 3)$ & $6 \cdot 0(0.3,368 \cdot 3)$ \\
\hline \multicolumn{6}{|l|}{ Father: } \\
\hline Exposure to pesticides (yes /no) & 43 & 41 & $1 \cdot 1(0 \cdot 4,3 \cdot 0)$ & $1 \cdot 1(0 \cdot 3,4 \cdot 1)$ & $1 \cdot 0(0 \cdot 2,6 \cdot 1)$ \\
\hline Exposure to pesticides ( $\geq 3 \mathrm{~h} / \mathrm{wk}$ ) & 36 & 16 & $3 \cdot 2(1 \cdot 0,10 \cdot 1)$ & $2 \cdot 9(0 \cdot 7,13 \cdot 0)$ & $2 \cdot 1(0 \cdot 4,12 \cdot 5)$ \\
\hline \multicolumn{6}{|l|}{ Pesticides sum score: } \\
\hline$>2$ parameters & 36 & 38 & $1 \cdot 7(0 \cdot 6,5 \cdot 5)$ & $0 \cdot 9(0 \cdot 2,3 \cdot 7)$ & $0 \cdot 8(0 \cdot 1,4 \cdot 4)$ \\
\hline$>3$ parameters & 29 & 20 & $1 \cdot 6(0 \cdot 5,4 \cdot 5)$ & $1 \cdot 6(0 \cdot 4,7 \cdot 4)$ & $1 \cdot 7(0 \cdot 3,10 \cdot 5)$ \\
\hline$>4$ parameters & 21 & 7 & $5 \cdot 0(1 \cdot 0,24 \cdot 2)$ & $3 \cdot 6(0 \cdot 4,23 \cdot 9)$ & $3 \cdot 1(0 \cdot 3,28 \cdot 3)$ \\
\hline \multicolumn{6}{|l|}{ Water sports ( $>5$ y of age) } \\
\hline Swimming west & 20 & 28 & $0 \cdot 6(0 \cdot 2,2 \cdot 1)$ & $0 \cdot 7(0 \cdot 1,4 \cdot 4)$ & $2 \cdot 7(0 \cdot 2,43 \cdot 0)$ \\
\hline Swimming east $\geq 1 \mathrm{~h} / \mathrm{wk}$ & 60 & 28 & $5 \cdot 3(1 \cdot 3,17 \cdot 4)$ & $4 \cdot 0(0 \cdot 8,22 \cdot 3)$ & $3.8(0 \cdot 5,45 \cdot 6)$ \\
\hline Swimming east $\geq 2 \mathrm{~h} / \mathrm{wk}$ & 50 & 15 & $4.5(1 \cdot 4,14 \cdot 0)$ & $5 \cdot 7(1 \cdot 0,34 \cdot 6)$ & $4 \cdot 3(0 \cdot 6,37 \cdot 2)$ \\
\hline \multirow{2}{*}{\multicolumn{6}{|c|}{$\begin{array}{l}\text { Air pollution } \\
\text { Nuisance: }\end{array}$}} \\
\hline & & & & & \\
\hline General annoyance & 86 & 50 & $5 \cdot 0(1 \cdot 5,28 \cdot 0)$ & $6 \cdot 0(1 \cdot 2,58 \cdot 7)$ & $2 \cdot 7(0 \cdot 4,30 \cdot 1)$ \\
\hline $\begin{array}{l}\text { Aircraft annoyance } \\
\text { Outdoor activities: }\end{array}$ & 79 & 45 & $3 \cdot 7(1 \cdot 4,16 \cdot 7)$ & $4 \cdot 6(1 \cdot 0,27 \cdot 6)$ & $1 \cdot 8(0 \cdot 3,13 \cdot 4)$ \\
\hline \multicolumn{6}{|l|}{ Outdoor activities: } \\
\hline $\begin{array}{l}\text { Outdoor recreation ( } \geq 10 \mathrm{~h} \mathrm{wk} \text { ) } \\
\text { Idem, minus swimming }\end{array}$ & 71 & 43 & $8 \cdot 0(1 \cdot 3,26 \cdot 9)$ & $3 \cdot 3(0 \cdot 8,16 \cdot 1)$ & $2 \cdot 3(0 \cdot 4,13 \cdot 6)$ \\
\hline \multirow{2}{*}{\multicolumn{6}{|c|}{ Local vegetable consumption: }} \\
\hline & & & & & \\
\hline $\begin{array}{l}\geq 2 \times \text { per week } \\
\geq 4 \times \text { per week }\end{array}$ & 50 & 32 & $2 \cdot 1(0 \cdot 6,8 \cdot 2)$ & $2 \cdot 1(0 \cdot 6,8 \cdot 2)$ & $1 \cdot 9(0 \cdot 3,11 \cdot 5)$ \\
\hline$\geq 4 \times$ per week & 43 & 18 & $3 \cdot 0(1 \cdot 1,11 \cdot 1)$ & $3 \cdot 5(0 \cdot 8,14 \cdot 7)$ & $4 \cdot 0(0 \cdot 6,27 \cdot 1)$ \\
\hline
\end{tabular}

Matched = matched for age and gender; Crude = unmatched and unstratified; Stratified=stratified for residence in the eastern of two neighbourhoods with reasonable proximity to greenhouses and suspect pond. 
general practitioner led, more or less, to matching on neighbourhood. To further reduce confounding, ORs were calculated, stratified by neighbourhood.

In addition to confounding, the results of case-control studies can be biased by differences in the selection of cases and controls and differences in the way information is gathered.

To prevent any differences in response between patients and controls, all participants in the study were motivated as strongly as possible by a letter signed by the general practitioner. The high response showed the success of this. The average time spent on filling out the questionnaire was comparable for the patient and the control groups.

Sometimes patients tend to remember certain suspect factors selectively. ${ }^{10}$ The specifically local aspects were therefore embedded in a more general setting. Furthermore, the research received no advance publicity. The contaminated pond was suspect only to the family who had raised the alarm. When this family was excluded, however, the OR remained high (3.5). Moreover, the interviewer did not have the impression that case families exaggerated their exposures, which were usual in the community.

Bias can occur further if the interviewer knows who is a patient and who a control. Families were therefore asked to complete the questionnaire before discussing it with the interviewer. Discussing the completed questionnaire anonymously was not possible in view of the nature of the subject.

Bias could also have arisen from the fact that exposure could not be directly measured. Estimates of indirect exposure parameters such as the number of hours or years of contact (or both) with specific chemical substances had to suffice. All the estimates that could be checked, such as proximity of the house to greenhouses, were found to be well represented in the questionnaire.

Too little is known about the latency period of haematopoietic malignancies to determine the most relevant exposure period at an individual level. There is no reason to assume, however, that exposure was systematically measured differently for the case group and the control group; this indifferent misclassification for exposure probably resulted in an underestimation of the crude ORs.

Another complicating and unavoidable aspect of a case-control study under these circumstances is the unfavourable balance between the number of matched groups observed (14) and the number of questions asked (45 if viewed uncombined). By combining answers to exposures such as to pesticides and water sports, a reduction in the number of variables was attempted. In spite of stratification for neighbourhood, a certain colinearity of the exposure variables is likely and has to be taken into account in evaluating the total pattern of results, especially the interpretation of the calculation of aetiological fractions. A clear colinearity was encountered for swimming and exposure to pesticides. The association between the occurrence of the illness and swimming was less if exposure to pesticides in (own or fathers) work was taken into account.

Partly because of the possibilities of bias, observed statistical relationships in case-control research can not simply be interpreted as causal relationships. This is especially true for this study, in which the OR confidence intervals are rather wide because of the small numbers. To evaluate the causality of the association, the results will be compared with other epidemiological research.

The age distribution of the leukaemia and lymphoma cases corresponds with national data. " The ratio between leukaemia and lymphoma was not extreme (1:1, compared with an expected ratio of $0 \cdot 7: 1$ ). The gender distribution was distorted: the male-female ratio was $6: 1$ and this ratio is usually $1.9 .{ }^{11}$ In spite of the small numbers involved, this could fit the boys' activity pattern, as they are more exposed to local environmental factors than girls.

Although the investigation was not meant to test the hypothesis of an infectious aetiology for childhood leukaemia, the data did not seem to support this - only some children were attending the same school or general practice during the same period and affected adults or fathers were not concentrated within the same workplaces or employers. Except for two leukaemia cases, who used to swim and play together (in the garage) and went to the same primary school, there was no social contact between the cases before diagnosis. In contrast to Kinlens New Towns, ${ }^{12}$ Aalsmeer is a stable society, with no large influx of people.

The ORs for acknowledged risk indicators were in good agreement with those from a large scale Dutch case-control study $(n=519$, 507 respectively) by Van Steensel-Moll. ${ }^{13}$ Only the ORs for chemical exposure at the father's workplace were clearly higher than in the Van Steensel-Moll study.

The association between haematological malignancies and exposure to pesticides has been described before in published epidemiological studies. ${ }^{14-16}$ The fact that the ORs were higher here than in the Van Steensel-Moll study could be explained by the fact that exposure is more intensive in flower cultivation than in agriculture and horticulture in general. ${ }^{17}$ Qualitatively, exposure to pesticides in flower cultivation also contrasts unfavourably with the cultivation of food crops. On the other hand, in the same five year period no increase in deaths from leukaemia was observed in several other horticultural areas. ${ }^{6}$

The results indicate that a causal relationship with the pollution of the water recreation area cannot be ruled out. Sediment samples, taken afterwards from the suspect pond, contained concentrations of the persistent organochloride compounds DDT and endrin known carcinogens in animal studies - that were 20 fold those in the other pond. According to the National Institute of Public Health and Environmental Protection (RIVM) the concentrations currently found do not represent an unacceptable risk for human cancer 
(written communication RIVM, 1989). In the period covered by the study, however, exposure was probably much higher because of accidental spillages. In the neighbourhood of a Scottish nuclear power plant, a relation between swimming in polluted water and the occurrence of childhood leukaemia and lymphoma has also been suggested. ${ }^{18}$ Swimming could not have been the only risk factor, however, as a number of patients had never swum there.

The possible aetiological influence of local air pollution was difficult to investigate because there is insufficient variation in (annoyance from) air pollution within Aalsmeer. Still, there was some variation in the chosen indirect measurements of exposure. Because increased ORs were recorded and haematopoietic malignancies in young people in the neighbouring municipality were also increased during the research period, ${ }^{6}$ this hypothesis cannot be rejected directly. Of all of the questionnaire data, however, the degree of annoyance is most likely to suffer from reporting bias, because the planned expansion of Schiphol airport was regularly in the news at that time.

In general, case-control research into disease clusters in a local population is seldom indicated because of the usually small numbers and the potential bias. In only a few studies have local environmental factors made a plausible contribution to the occurrence of diseases. Conditions for this type of research are: at least five patients with a homogeneous clinical picture, a strongly increased incidence, sufficient variation in exposure, easily quantifiable exposure, and minimal publicity. ${ }^{1920}$ Our investigation largely met these conditions. The margins of uncertainty produced by the unavoidably small numbers have to be taken into consideration. They are particularly evident when a small area is reduced even further in size by stratification into neighbourhoods. The possibility, however, that a number of specific local environmental factors contributed to an increased incidence of haematopoietic malignancies in young people in Aalsmeer cannot be ruled out.

Recommendations for evaluating the carcinogenic risks from the PAH contamination of swimming water, air, and vegetables have all been carried out, but current concentrations did not show an unacceptably increased risk. A follow up among general practitioners showed that the incidence of haematopoeitic malignan- cies returned to normal after 1985, so if there has been a relation, it will probably be a relation with past exposure.

The study results have also been published in a Dutch medical journal: Mulder YM, Drijver M, Kreis IA. Patient-controlejournal: Mulder YM, Drijver M, Kreis IA. Patient-controleonderzoek naar het verband tussen lokale milieufactoren en hematopoetische maligniteiten bij

Financial support for this investigation was received from the Authority for Public and Environmental Health and the municipality of Aalsmeer. This study was made possible by the cooperation of local general practitioners and the Community Health Service Amstelland De Meerlanden, where the medical officer, B Kok, played an important coordinating role. Thanks are also due to B Brunekreef, E I M Florack, F E van Leeuwen, Dr M M Verberk, and Dr J H van Wijnen for their valuable advice during design, analyses, and interpretation of the study.

1 Linet MS. The leukemias: epidemiologic aspects. Monographs in epidemiology and biostatistics. Volume 6 . Oxford: Oxford University Press, 1985.

2 Gardner MJ. Review of reported increases of childhood cancer rates in the vicinity of nuclear installations in the cancer rates in the vicinity of nuclear

3 Cutler JJ, Parker GS, Rosen S, Prenney B, Healey R Caldwell GG. Childhood leukemia in Woburn, Massachusetts. Public Health Reports 1986;101:201-5.

4 Lagakos SW, Wessen BJ, Zelen M. An analysis of contaminated well water and health effects in Woburn, Massachusetts. F Am Stat Assoc 1986;81:583-614.

5 Savitz DA, Feingold L. Association of childhood cancer with residential traffic density. Scandinavian fournal of Work and Environmental Health 1989;15:360-3.

6 Mulder YM, Drijver M. Leefgewoonten, gezondheid en woonomgeving. Een milieu-epidemiologisch onderzoek naar de relatie tussen omgevingsfactoren en kanker bij jongeren in de relatie tussen omgevingsfactoren en kanker bij jongeren in de gemeente Aalsmeer. (In Dutch). Amstelveen: Bas

7 Coebergh JWW. Incidence and prognosis of cancer in The Netherlands: studies based on cancer registries. Rotterdam: Netherlands: studies based on cancer regist

8 Breslow NE, Day NE. Statistical methods in cancer research

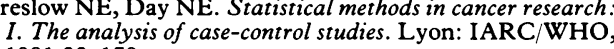
1981:22-159.

9 Miettinen OS. Proportion of disease caused or prevented by a given exposure, trait or intervention. Am $\mathrm{f}$ Epidemiol 1974;99:325-32.

10 Anonymous. Disease clustering: hide or seek? Editorial. Lancet 1990;336:717-8.

11 Centraal Bureau voor de Statistiek, Ministerie van WVC. Compendium gezondheidsstatistiek Nederland 1986. (In Dutch). 's-Gravenhage: Staatsuitgeverij, 1986:284-5.

12 Kinlen LJ, Clarke K, Hudson C. Evidence from population mixing in British new towns 1946-85 of an infective basis mixing in British new towns 1946-85 of an infective

13 Steensel-Moll HA van. Childhood leukemia in the Netherlands; a register based epidemiologic study. Rotterdam:

14 Corrao G. Cancer risk in a cohort of licensed pesticide users. Scandinavian fournal of Environmental Health 1989;15:203-9.

15 Weisenburger D. Environmental epidemiology of nonHodgkin's lymphoma in eastern Nebraska. American fournal of Industrial Medicine 1990;18:303-5.

16 Crane MM, Keating MJ. Exposure histories in acute nonlymphocytic leukemia patients with prior preleukemic condition. Cancer 1991;67:2211-4.

17 Berends, AG. Bestrijdingsmiddelen en oppervlaktewaterkwaliteit; een inventarisatie van het gebruik van bestrijdingsmiddelen in de akkerbouw en tuinbouw. (In Dutch). Lelystad: RIZA, 1988:105-6.

18 Urquhart JD, Black RJ, Muirhead MJ, Sharp L, Maxwell M, Eden OB, Jones DA. Case-control study of leukaemia and non-Hodgkin's lymphoma in children in Caithness and non-Hodgkin's lymphoma in children in Caithness
near the Dounreay nuclear installation. BMJ

19 Rothman KJ. A sobering start for the cluster buster's conference. Am $\mathcal{F}$ Epidemiol 1990;132(Suppl):S6-13.

20 Neutra RR. Counterpoint from a cluster buster. Am $f$ Epidemiol 1990;132:1-8. 